\title{
Cross-Country Differences in How Behavioral Biases Affect Decision-Making in the Bank Industry: Evidence from Italy and Serbia
}

\author{
Mario Mustilli ${ }^{1}$, Rossana Piccolo ${ }^{1}$, Eugenio D'Angelo ${ }^{2}$ \\ ${ }^{1}$ Department of Economics, University of Campania, Capua, Italy \\ ${ }^{2}$ Department of Legal and Economic Science, Pegaso Telematic University, Naples, Italy \\ Email: mario.mustilli@unicampania.it,rossana.piccolo@unicampania.it, eugenio.dangelo@unipegaso.it
}

How to cite this paper: Mustilli, M., Piccolo, R. and D'Angelo, E. (2018) CrossCountry Differences in How Behavioral Biases Affect Decision-Making in the Bank Industry: Evidence from Italy and Serbia. American Journal of Industrial and Business Management, 8, 239-249.

https://doi.org/10.4236/ajibm.2018.82016

Received: January 17, 2018

Accepted: February 9, 2018

Published: February 12, 2018

Copyright $\odot 2018$ by authors and Scientific Research Publishing Inc. This work is licensed under the Creative Commons Attribution International License (CC BY 4.0).

http://creativecommons.org/licenses/by/4.0/

\begin{abstract}
Since non-performing loans, despite the implementation of the Basel accords, which should have improved creditworthiness estimation, are strongly affecting European banks' liquidity and stability, there could be a behavioral bias behind banks misallocation of capital. The purpose of this study is to investigate whether behavioral biases affect credit allocation in different ways in different countries. Particularly, we investigated how certain characteristics of the applicants, such as race, age, gender and education, affect bank officers' decision-making process. The study was conducted submitting face-to-face questionnaires to 299 officers, 212 in Italy and 87 in Serbia, working in the credit chain. Running a Mann-Whitney $U$ test on the mentioned two independent samples, result show that Italian officers are more influenced by behavioral biases than their Serbian colleagues when they have to decide whether or not to approve a loan application.
\end{abstract}

\section{Keywords}

Banks, Behavioral Biases, Italy, Serbia

\section{Introduction}

The relationships between behavioral models and real facts have led more and more scholars to areas of knowledge that are too important to be neglected and too realistic to not be investigated. The "Homo Oeconomicus" paradigm, which has always characterized the traditional approach, seeing individuals as perfectly rational agents, comes to a more realistic view in which people make mistakes. Therefore scholars are trying to explain the so-called "anomalies" of the financial 
markets through a behavioral approach. The aim of behavioral economics is to make investors aware of the potential "psychological pitfalls" in which financial managers may incur during their decision-making process. This is because they use approximate rules, such as heuristics, which make it possible to simplify complex decision-making problems. This allows decision makers to shape the difficulty of a task to the limited capacity of collecting and processing the available information. Said traps have been described, among the others, by Tversky and Kahneman, allowing to analyze, in a systematic way, apparently irrational behaviors that economists define as "distortions" or "biases" [1]. In this context, the financial crises that have occurred in recent years can be taken in account and analyzed using this behavioral approach. Of course the financial crisis had highlighted, among other challenging questions concerning the financial system, the weakness of the European bank industry. Banks are facing a huge amount of non-performing loans that, according to the Basel Committee, is due to the weakness of the Basel II accord, which has been integrated by the Basel III one and soon will be integrated by the Basel IV accord. These mechanisms tend to strengthen the solidity of banks through a more stringent creditworthiness assessment system and through the introduction of a series of parameters aimed to increasing stability and liquidity of the banking system. Thus not enough space has been given to the possibility that bank officers may have been influenced by behavioral biases when deciding to accept or reject a loan application. On the contrary we believe that behavioral biases may have contributed to the bank crisis leading officers to a misallocation of the funds. In other words, an adverse selection caused by prejudices regarding some characteristics of the applicants could have occurred, contributing to the increase in non-performing loans. Of course these behavioral biases may have had a different effect in different countries. The European banking system has experienced a highly challenging problem concerning the capacity of debt holders to guarantee the repayment of their obligations. Italy and Serbia, in particular, had a similar trend in recent years concerning non-performing loans. Italy's non-performing loans ratio is now $14.2 \%$ while the Serbian one is $12.2 \%$ (September 2017). Both data are improving since the previous detection (2015), which were $17.1 \%$ in Italy and $23 \%$ in Serbia, but still far from the best performances reached in 2008, when the Italian non-performing loans were $5 \%$ and Serbian ones were $10.2 \%$. Even if the financial crisis had similar trends over Italians and Serbians banks, there is a main difference between these two countries that may need a more in depth analysis concerning potential behavioral biases in the credit allocation process. This is mainly relative to the competition in the credit industry and to the evolving process of the banking system. In Italy the credit industry is mostly concentrated in five bank groups: Unicredit, Intesa Sanpaolo, MPS, UBI and UBM, on the other side, in Serbia, the bank industry is composed of only 30 banks, seven of them are local banks (6 state owned and 1 private bank) and 23 are foreign owned banks [2]. If we look at the total asset composition of the bank industry, 
no one of them exceeds the $13 \%$ of the total amount of the asset invested in the bank industry. Furthermore, since 2001 the Serbian banking system had changed substantially, ending with a reduction in the number of state owned banks and with an important process of licenses revocation by the National Bank of Serbia [3]. The overall process, according to previous literature, may have led to a more competitive environment, which usually is associated with better performances. Therefore, the purpose of this paper is to investigate the different way in which behavioral biases affect the credit decision-making process in two dissimilar contexts such as the Italian and the Serbian one. The paper is organized in the following way. The second section is dedicated to the literature review concerning the behavioral biases analyzed in the empirical analysis. Data gathering and methodology is described in section three. The results of the empirical analysis are reported in the fourth section. The last section of the paper is dedicated to the contribution of the paper, the limitations and some hypotheses of future research.

\section{Literature Review and Research Hypotheses}

The behavioral approach to finance dates back to the mid-seventies with the works of Daniel Kahneman and Hersh Shefrin, who were the first to realize that this new approach to finance would have represented the new frontier of corporate finance [4]. The traditional theories of finance are based on the assumptions of rationality, efficient market and profit maximization. This is because the classical theory states that the agents set up unperturbed predictions about the future and decide by correctly assessing their interests. Managers take for granted that markets are efficient and that prices reflect fundamental values [5]. In fact, economists base their models on the basis of the behavior of individual actors, endowed with perfect rationality and unlimited information capacity [6]. These theories, however, cannot explain the daily chaotic and abnormal phenomena in the "real" market [7]. It is precisely on these bases that a new line of research opens up: the behavioral finance. This shows how the behavior of people does not reflect the axioms of rationality underlying traditional finance [8]. Behavioral finance is a part of a growing interest in the relationship between finance and human behavior [9]. Everything starts from the human being and from the way people make decisions every day, combining different theories from the areas of classical economics, finance and psychology. Investor decisions are often influenced by psychological factors, which arise and develop in the mind of the individual. The behavioral economics, therefore, tries to integrate the classical theory that includes the rational choices of individuals with new models, based on psychological studies, considering that phenomena of market anomalies that appear irrational are more and more frequent. Mental errors are often due to the limits in the number of available information and to the capability to process information and, when it comes to analyze the main behavioral biases that may affect credit issuance, scholars have often referred to four typical prejudices such as 
gender, age, education and race. We've summarized and reported below some important research contribution concerning these behavioral biases.

Gender: In the field of behavioral economics studies, the theme linked to gender has always been relevant. Based on a large body of literature, which investigates the determinants of gender discrimination in the credit market, Galli and Ross provide descriptive analyzes related to women's access to credit, with reference to a sample of 11 European countries [10]. It is clear that, on the demand side, women's businesses are asking for lower bank loans than the male ones and one of the determining factors for their decision not to apply is the fear of rejection. Kucuk and Candemir in their study, explore on gender bias in access to loans in 147 countries showing how increasing gender equality leads to a higher share of loans from women [11]. Estimates show that improvements in gender equality and growth have a positive impact on access to financial institutions' lending services. Calcagnini, Giombini and Lenti show how entrepreneurs report difficulties in accessing bank credit as a result of supply-side discrimination [12]. Differences in access to credit are the result of discrimination and structural differences between companies owned by men and women. Policies to improve the access of female-owned businesses to bank loans should encourage an increase in the size of the enterprise that is often associated with the adoption of more sophisticated corporate legal structures.

Age: Age is one of the most studied factors influencing access to bank loans. Nakano and Nguyen show how the impact on access to bank loans is affected by this bias and it can be analyzed both on the demand side and on the supply side of the loan. From the point of view of demand, age is a factor that determines the manager's preference to be a user or a non-user in the credit market. A "particular" age group tends to behave differently than other age groups, for example, older owners appear to be less inclined to bank lending. From the supply point of view, Abdulsaleh and Worthington recognize the perception that banks have different attitudes to different age groups, thus affecting access to bank loans. In some cases older entrepreneurs are generally perceived as non innovative and not very dynamic, which may results in a higher rejection rate if the bank has a higher risk aversion [13].

Education: There are several studies that agree with the view that the quality of human capital increases with the degree of training of the applicant. Abdulsaleh and Worthington assert that those with higher education are more likely to have access to bank loans than those who do not. Zarook et al. and Slavec and Prodan have discovered that managers' level of education has a significant positive correlation with access to bank loans [13] [14] [15]. Pandula also shows that the educational background has a significant relationship with access to bank loans [16].

Race: Racial diversity has been studied several times in recent years. Cloud and Galster summarize the evidence relating to acts of racial discrimination in the mortgage credit market [17]. They show that, although many unanswered questions remain about the extent and nature of racial discrimination in mort- 
gage credit, there is sufficient evidence to conclude that the problem still exists. Storey highlights a racial disparity in the decision to issue loans in the market for loans from banks to small and medium-sized businesses in Trinidad and Tobago. Africans have reported higher rejection rates than other ethnic groups [18].

Summing up, according to previous literature in the field of behavioral finance, it seems that younger and less educated applicants suffer a higher rejection rate when they apply for a loan and that similar circumstances affect female and ethnical minorities. We decided to investigate the differences in the access to credit in two different banking industries: Serbia and Italy. According to the increasing competition of the Serbian credit sector, described in the introduction of the paper, we assume that Serbian officers may have been more focused on the fundamental analysis and, therefore, less influenced by behavioral biases. Consequently, we've formulated only one research hypothesis as follows:

Hp) Bankofficers working in the Serbian environment perceive to be less influenced by behavioral bias than their colleagues working in the Italian credit chain.

\section{Materials and Methods}

Since the aim of this paper was to investigate whether the Serbian bank officers perceive to be more or less influenced by behavioral biases in their decision to accept or reject a loan application, we firstly needed to measure, for both countries, the perceived influence of some typical behavioral biases. To fulfill this need, we've submitted 299 questionnaires to Italian and Serbian officers, but this large difference in the number of samples does not affect the results of the study since the test we used can be conducted over different sample sizes. The Italian sample involved 212 managers, working in the credit initiation and authorization process of the following 12 banks: Artigiancassa, Banca Apulia, Banca del Sud, BCC, Banca di credito cooperative dell'Alto Casertano e Basso Frusinate, Banca di Sconto e Conti Correnti, Banca di Verona, Banca Fideuram, MPS, BNL, Banca Popolare del Mediterraneo, Banca Popolare dell'Emilia Romagna, Banca Popolare di Ancona, Banca Popolare di Puglia e Basilicata, Banca Popolare Etica, Banca Promos, Banca Sella, Cariparma, Credem, Deutsche Bank, Intesa Sanpaolo, MPS Capital Service, Unipol, Unicredit and Widiba. The Serbian sample consisted of 87 officers, working in the following banks: Addiko Bank Ad Beograd, Alpha Bank Srbija Ad Beograd, Banca Intesa Akcionarsko Društvo Beograd, Banka Poštanska Štedionica Akcionarsko Društvo, Direktna Banka Akcionarsko Društvo Kragujevac, Erste Bank Akcionarsko Društvo, Eurobank Akcionarsko Društvo Beograd, Halkbank Akcionarsko Društvo Beograd, Jubmes Banka Ad Beograd, Jugobanka Jugbanka Ad Kosovska Mitrovica, Marfin Bank Akcionarsko Društvo, Beograd, Mirabank Akcionarsko Društvo Beograd, Mts Banka Akcionarsko Društvo Beograd, Nlb Banka Ad, Otp Banka Srbija Akcionarsko Društvo, Piraeus Bank Akcionarsko Društvo Beograd, Raiffeisen Banka Ad Beograd, Sberbank Srbija A.D. Beograd, Srpska Banka Ad Beograd, Telenor 
Banka Ad Beograd, Unicredit Bank Srbija A.D., Vojvođanska Banka Akcionarsko Društvo, Vtb Banka Akcionarsko Društvo Beograd, Bankoma. Among the Serbian banks, three of them are state owned (notably: Poštanka Banka, Srpska Banka and Jubmes Banka), while no state owned banks are included in the Italian sample. The overall data gathering process last 5 months, from May to September 2017, which included the time needed for the preparation of the survey, for submission and, finally, for the analyzing data. Some extra time was dedicated to the pre-testing, to assess the cogency of the questionnaire design and fill some gaps. As we pointed out in the previous section, we chose four behavioral biases (age, gender, education and race) that in the previous literature have been widely studied and with respect to which there is a substantial convergence in considering them of significant impact in the provision of credit. Therefore we've submitted a questionnaire, using a 10-point rating scale, which is commonly used in survey research, asking to each single officer to indicate, for each specific item concerning the applicants' characteristics (again: age, gender, education and race), if they perceive to be more or less influenced by any given item, when it comes to the decision to accept or reject a loan application. In this way, for each officer, we had a measure of how they perceive to be influenced by every single item. The Likert responses can be analyzed separately or summed one another, in order to have a comprehensive score. According to our purpose, we create a score, named "behavioral score" which is the sum of the response given by every single officer to each question. As far as the measurement of the perceived influence of the behavioral biases as a whole is concerned, we use this score as the main indicator to demonstrate our hypothesis. Therefore we had two independent samples, the Italian one and the Serbian one, and we wanted to verify that the former had a higher behavioral score than the latter. To test this hypothesis we used the Mann-Whitney U test. We can use this non-parametric test since we had one dependent variable that is measured at the ordinal level (Likert score values reported for each officer), we had to categorical independent groups (Italian and Serbian), we had independence of observations, which means that there is non relationship between the observations of the two groups and lastly because the two behavioral scores distributions had different shapes. We've used SPSS 17 to process data.

\section{Results and Discussion}

Before running the Mann Whitney $U$ test, we analyzed the descriptive statistics concerning the single investigate items reported below (Table 1). Data show that Italian officers, compared to Serbian ones, declared that three out of four behavioral biases have a higher impact on their credit decision. Actually, both mean and median indicators resulted higher for the officers working in the Italian credit chain. Comparing the median indicators, the Italian officers give the highest importance to age, which had a median of 8 whereas the same indicator had a median of 5 for the Serbian group. Gender and race reported respectively a 
Table 1. Descriptive statistics concerning the single items.

\begin{tabular}{|c|c|c|c|}
\hline & \multicolumn{3}{|c|}{ Italy } \\
\hline & Median & Mean & var \\
\hline Gender & 7.00 & 5.60 & 6.70 \\
\hline Age & 8.00 & 7.01 & 4.68 \\
\hline Race & 5.00 & 5.21 & 4.25 \\
\hline Education & 5.00 & 5.45 & 3.91 \\
\hline Behavioral score & 25.00 & 23.27 & 48.93 \\
\hline \multicolumn{4}{|c|}{ Serbia } \\
\hline Median & & & Var \\
\hline 6.00 & & & 6.00 \\
\hline 5.00 & & & 2.72 \\
\hline 4.00 & & & 4.35 \\
\hline 6.00 & & & 3.04 \\
\hline 16.00 & & & 10.19 \\
\hline
\end{tabular}

Source: Author's calculation on data collected from the questionnaires.

median of 7 and 5 for the Italian officers and a median of 6 and 4 for the Serbian ones. On the contrary, education seems to be more likely to affect the credit decision-making process in Serbia rather than in Italy.

When it comes to the descriptive statistics concerning the behavioral scores (Table 2), which is the sum of the results reported in the single four items investigated, the 212 Italian observations reported a median of 25 and a mean of 23,27 whereas the 87 Serbian officers reported a median score of 16 and a mean of 15,86 . With a relatively high difference, supporting our hypothesis that Italian officers may be more affected by these behavioral biases.

Both the indicator of skewness and kurtosis resulted higher for the Italian group, which appears even clearer looking at the histograms concerning the frequency distributions (Figure 1).

In order to verify if our hypothesis is supported, as mentioned in the previous section of the paper, we ran a Mann Whitney $U$ test whose results are shown in the following table (Table 3). The table shows the mean and the sum of ranks for the two groups, which is 179.24 for the Italian group and 78.76 for the Serbian one. This means a higher perceived influence of behavioral biases on the credit decision-making process for the Italian officers and this is consistent with our hypothesis. Furthermore, the table shows the test statistics, which reports the Mann-Whitney $\mathrm{U}$ and the Wilcoxon W.

The Mann-Whitney U reported a highly significant value of 3024 and, since the smaller value of the test means a higher difference between the two groups, we can say that the hypothesis we have tested is supported.

\section{Conclusion}

Serbia, as well as Italy, has suffered in recent years the effect of increasing non- 
Table 2. Descriptive statistics concerning the behavioral score.

\begin{tabular}{|c|c|c|c|}
\hline \multicolumn{4}{|c|}{ Statistics } \\
\hline \multicolumn{4}{|c|}{ Behavioral score } \\
\hline \multirow{8}{*}{ Italy } & & Valid & 212 \\
\hline & $1 \mathrm{~N}$ & Missing & 0 \\
\hline & \multicolumn{2}{|c|}{ Mean } & 23.27 \\
\hline & \multicolumn{2}{|c|}{ Median } & 25.00 \\
\hline & \multicolumn{2}{|c|}{ Skewness } & -0.859 \\
\hline & \multicolumn{2}{|c|}{ Standard error-Skewness } & 0.167 \\
\hline & \multicolumn{2}{|c|}{ Kurtosis } & 0.404 \\
\hline & \multicolumn{2}{|c|}{ Standard error-Kurtosis } & 0.333 \\
\hline \multirow{8}{*}{ Serbia } & \multirow{2}{*}{$\mathrm{N}$} & Valid & 87 \\
\hline & & Missing & 0 \\
\hline & \multicolumn{2}{|c|}{ Mean } & 15.86 \\
\hline & \multicolumn{2}{|c|}{ Median } & 16.00 \\
\hline & \multicolumn{2}{|c|}{ Skewness } & -0.293 \\
\hline & \multicolumn{2}{|c|}{ Standard error-Skewness } & 0.258 \\
\hline & \multicolumn{2}{|c|}{ Kurtosis } & 0.002 \\
\hline & \multicolumn{2}{|c|}{ Standard error-Kurtosis } & 0.511 \\
\hline
\end{tabular}

Source: Author's calculation on data collected from the questionnaires.

Table 3. Mann-whitney U test.

\begin{tabular}{|c|c|c|c|c|}
\hline \multicolumn{5}{|c|}{ Ranks } \\
\hline & Group & $\mathbf{N}$ & Mean Rank & Sum of Ranks \\
\hline & Italy & 212 & 179.24 & 37.998 \\
\hline \multirow[t]{2}{*}{ Behavioral score } & Serbia & 87 & 78.76 & 6.852 \\
\hline & Total & 299 & & \\
\hline \multicolumn{5}{|c|}{ Test } \\
\hline \multicolumn{5}{|c|}{ Behavioral score } \\
\hline \multicolumn{2}{|c|}{ Mann-Whitney U } & & \multicolumn{2}{|c|}{3.024} \\
\hline \multicolumn{2}{|c|}{ Wilcoxon W } & & \multicolumn{2}{|c|}{6.852} \\
\hline \multicolumn{2}{|c|}{$\mathrm{Z}$} & & \multicolumn{2}{|c|}{-9.138} \\
\hline \multicolumn{2}{|c|}{ Asymp. Sig. (2-tailed) } & & \multicolumn{2}{|c|}{0.000} \\
\hline
\end{tabular}

Source: Author's calculation on data collected from the questionnaires.

performing loans on its balance sheets. The increase of non-performing loans, given the implementation in both countries of the Basel agreements on credit, that should have improved the ability to estimate creditworthiness, has opened a 


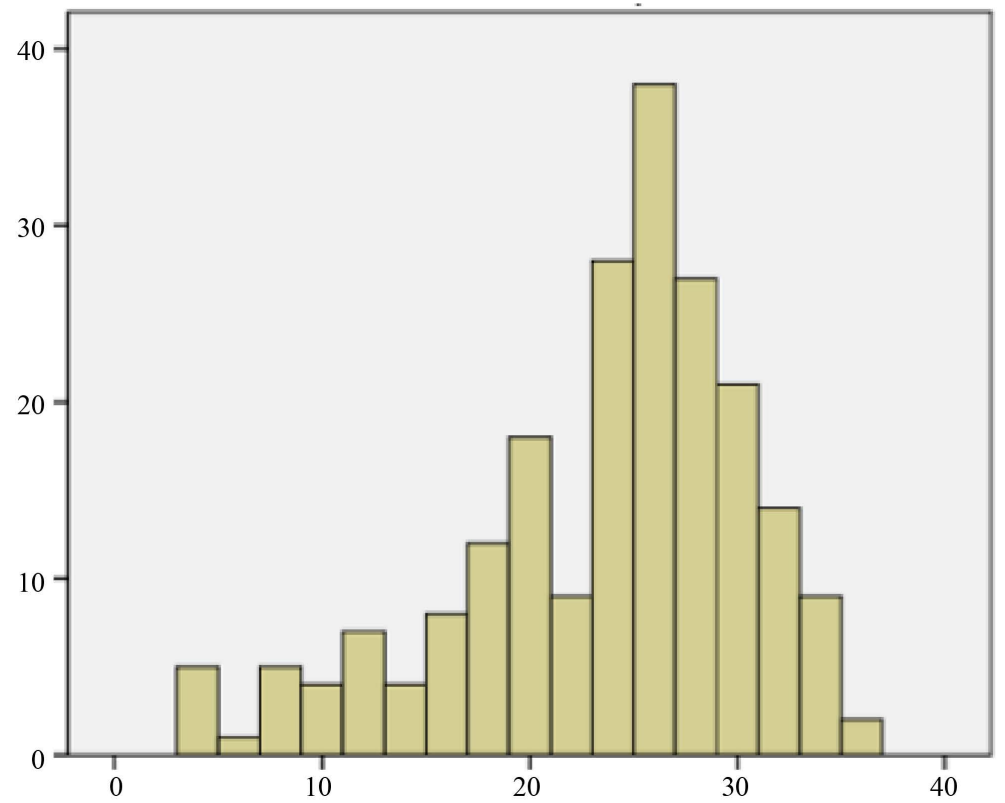

(a)

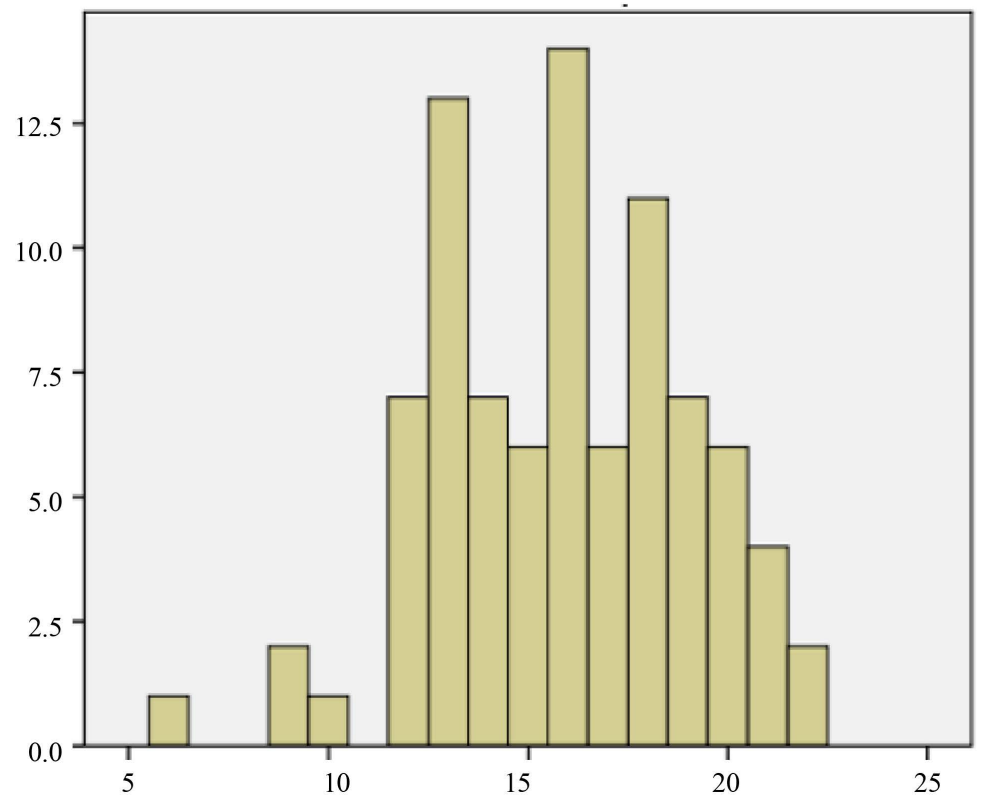

(b)

Figure 1. Behavioral scores frequency distributions.

discussion about the possibility that the adverse selection made by banks in credit allocation may have been due not so much to an error in estimating the reliability of the borrowers of funds, as to behavioral bias. This work is part of this stream of studies and in particular investigates how some of these behavioral biases can have different effects in different cultural and industrial contexts. The analysis showed that Italian officers are more susceptible than Serbian ones to prejudices against applicants. The main contribution of the paper is associated to the possibility to explain the adverse selection the credit allocation, which has 
driven to the huge amount of non-performing loans, through behavioral biases affecting bank officers. The study can certainly be improved through the extension of the sample to a larger number of respondents and through the use of a broader set of behavioral variables, such as, for instance, overconfidence. In addition it would be interesting to investigate whether the officers of the same banking groups operating in Italy and in Serbia, as in the case of Unicredit or Intesa Sanpaolo, are influenced in the same way by behavioral bias in assessing whether to accept or reject a credit application.

\section{References}

[1] Tversky, A. and Kahneman, D. (1992) Advances in Prospect Theory: Cumulative Representation of Uncertainty. Journal of Risk and Uncertainty, 5, 297-323. https://doi.org/10.1007/BF00122574

[2] National Bank of Serbia (2016) Banking Sector in Serbia. First Quarter Report, 1-34.

[3] Popovic, Z., Stankovic, J.-J. and Marjanovic, I. (2017) Analysis of Bank Efficiency in the Republic of Serbia. International Scientific Conference, 233-242.

[4] Shefrin, H. (2007) Finanza Aziendale Comportamentale: Decisioni per Creare Valore. Apogeo, 1-236.

[5] Spano', M. (2005) Macroeconomic Effects of Stock Market Fluctuations. Rivista Italianadegli Economisti, 375-396.

[6] Legrenzi, P. (2005) Creatività e Innovazione. Il Mulino, 1-129.

[7] Fama, E. (1970). Efficient Capital Markets: A Review of Theory and Empirical Work. The Journal of Finance, 25, 383-417. https://doi.org/10.2307/2325486

[8] Ferretti, R., Rubaltelli, E. and Rumiati, R. (2011) La Mente Finanziaria: Economia e Psicologia al Serviziodell'Investitore. Il Mulino, 1-310.

[9] Franzosini, G. and Franzosini, S. (2010) Finanza Comportamentale: Psicologiadelle Scelte. Libreria Universitaria Edizioni, 1-44.

[10] Galli, E. and Rossi, S. (2016) Bank Credit Access and Gender Discrimination: Some Stylized Facts. Springer, 111-123. https://doi.org/10.1007/978-3-319-17413-6_8

[11] Kucuk Dogan, N. and Candemir, M. (2013) Gender Bias in Access to Business Loans: A Cross Country Analysis. Kandin/Woman, 25-38.

[12] Calcagnini, G., Giombini, G. and Lenti, E. (2014) Gender Differences in Bank Loan Access: An Empirical Analysis. Italian Economic Journal, 1, 193-217. https://doi.org/10.1007/s40797-014-0004-1

[13] Abdulsaleh, A.-M. and Worthington, A.-C. (2013) Small and Medium-Sized Enterprises Financing: A Review of Literature. International Journal of Business and Management, 8, 1-36. https://doi.org/10.5539/ijbm.v8n14p36

[14] Zarook, T., Rahman, M.-M. and Khanam, R. (2013) Management Skills and Accessing to Finance: Evidence from Libya's SMEs. International Journal of Business and Social Science, 4, 106-115.

[15] Slavec, A. and Prodan, I. (2012) The Influence of Entrepreneur's Characteristics on Small Manufacturing Firm Debt Financing. Journal for East European Management Studies, 17, 104-130.

[16] Pandula, G. (2011) An Empirical Investigation of Small and Medium Enterprises. Access to Bank Finance: The Case of an Emerging Economy. Annual Conference, Proceedings of ASBBS, 18, 255-273. 
[17] Cloud, C. and Galster, G. (1993) What Do We Know about Racial Discrimination in Mortgage Markets? The Review of Black Political Economy, 22, 1-101. https://doi.org/10.1007/BF02689922

[18] Storey, D. (2004) Racial and Gender Discrimination in the Micro Firms Credit Market? Evidence from Trinidad and Tobago. Small Business Economics, 23, 401 422. https://doi.org/10.1007/s11187-004-7259-0 